\title{
Insight
}

\section{Social Resilience and Commercial Fishers' Responses to Management Changes in the Great Barrier Reef Marine Park}

\author{
$\underline{\text { Stephen G. Sutton }}^{1}$ and Renae C. Tobin ${ }^{1}$
}

\begin{abstract}
Understanding how social resilience influences resource users' responses to policy change is important for ensuring the sustainability of social-ecological systems and resource-dependent communities. We use the conceptualization and operationalization of social resilience proposed by Marshall and Marshall (2007) to investigate how resilience level influenced commercial fishers' perceptions about and adaptation to the 2004 rezoning of the Great Barrier Reef Marine Park. We conducted face-to-face interviews with 114 commercial and charter fishers to measure their social resilience level and their responses and adaptation strategies to the 2004 zoning plan. Fishers with higher resilience were more likely to believe that the zoning plan was necessary, more likely to be supportive of the plan, and more likely to have adapted their fishing business and fishing activity to the plan than were fishers with lower social resilience. High-resilience fishers were also less likely to perceive negative impacts of the plan on their fishing business, less likely to have negative attitudes toward the consultation process used to develop and implement the plan, and less likely to have applied for financial compensation under the structural adjustment program. Results confirm the utility of the social resilience construct for identifying fishers who are likely to be vulnerable to changes, and those who are struggling to cope with change events. We conclude that managing for social resilience in the GBR would aid in the design and implementation of policies that minimize the impacts on resource users and lead to more inclusive and sustainable management, but that further research is necessary to better understand social resilience, how it can be fostered and sustained, and how it can be effectively incorporated into management.
\end{abstract}

Key Words: commercial fishing; Great Barrier Reef; marine protected area zoning; social resilience

\section{INTRODUCTION}

Resilience theory has shown potential as the basis for developing inclusive and effective approaches to managing complex social-ecological systems (Berkes and Folke 1998, Levin et al. 1998, Marshall 2007). Resilience is the ability of a system to undergo change and still retain the same structure and function (Carpenter et al. 2001, Lebel et al. 2006). Socialecological systems with a high level of resilience are flexible, adaptable, and prepared for change and uncertainty (Gunderson 1999, Hughes et al. 2005).

Management frameworks based on resilience theory are an appealing option for designing novel approaches to natural resource management for a number of reasons. First, within a resilience-based management framework, managers are able to choose policy options that balance social costs with resource sustainability goals and choose options that are least likely to erode the resilience of the system, which would compromise its ability to cope with future changes (Holling and Meffe 1996, Holling et al. 1998, Holling 2004, Marshall and Marshall 2007). Second, resilience theory provides an integrative framework for combining research from the social and natural sciences in support of sustainable resource management (Berkes and Folke 1998). However, despite their apparent appeal, application of resilience-based frameworks within natural resource management has lagged behind the development of resilience theory, in part due to the difficulty of operationalizing the resilience concept and its components in complex and dynamic systems (Marshall and Marshall 2007).

Social resilience is an important component of resilience theory (Marshall and Marshall 2007, Marshall et al. 2007). Adger et al. (2002:358) defined social resilience as "the ability of communities to absorb external changes and stresses while maintaining the sustainability of their livelihoods." The resilience of resource-dependent individuals (e.g., commercial fishers) will determine how individuals and communities respond to changes in access to natural resources and the social and economic impacts of their responses to those changes (Marshall and Marshall 2007). Policies that take into account the resilience of resource users are likely to be more effective at achieving resource sustainability because social resilience is an important determinant of the willingness and capacity of resource users to adapt to new regulations and, more generally, to social and environmental changes (Marshall and Marshall 2007). Consequently, understanding how social resilience can be conceptualized and operationalized at the individual level is an important focus for research on the sustainability of social-ecological systems and resource-dependent communities.

Marshall and Marshall (2007), working with commercial fishing communities in Queensland, Australia, identified four key features of social resilience for individual fishers: (1) their perception of risk associated with change; (2) their ability to plan, learn, and reorganize; (3) their perception of their ability to cope; and (4) their level of interest in change. These authors 
also described a 12-item multidimensional scale used to operationalize their concept of social resilience. Application of the scale within the Queensland commercial fishing community revealed a positive relationship between social resilience and the way commercial fishers assess, appreciate, experience, and respond to prospective policy change (Marshall 2007). Furthermore, the combined effect of age, education, and attachment to occupation were found to be important determinants of social resilience in the commercial fisher population (Marshall et al. 2007). Further application of the social resilience concept and its associated measurement scale outside of the Queensland population (i.e., Salum, Egypt) suggested that social resilience can be useful for identifying and characterizing the vulnerabilities of stakeholder groups during the process of planning for prospective Marine Protected Areas (Marshall et al. 2009).

The research described above suggests that social resilience as conceptualized and operationalized by Marshall and Marshall (2007) can be valuable for understanding how commercial fishers and other resource users perceive and adapt to changes, and more generally for applying resilience theory to the management of complex social-ecological systems. However, the application of the social resilience concept thus far has been strictly prospective, i.e., to explore fishers' potential reactions and likely adaptations to hypothetical and generalized policy changes. It has not yet been tested whether high levels of social resilience translate into more positive perceptions of the impacts of, and better adaptation to, actual changes in resource management policy experienced by resource users. In this paper, we take a retrospective approach in which we examine the relationship between social resilience and commercial fishers' perceptions, attitudes, and adaptations regarding a major policy change that affected access to fisheries resources in the Great Barrier Reef Marine Park.

The Great Barrier Reef Marine Park (GBRMP) is a multipleuse marine park encompassing an area of approximately $345,000 \mathrm{~km}^{2}$ along the northeast coast of Queensland, Australia. The park is managed by the Australian Government's Great Barrier Reef Marine Park Authority (GBRMPA) with the primary goal of preserving and protecting the outstanding natural values of the Great Barrier Reef (GBR) while providing for wise use, understanding, and enjoyment of the area (Great Barrier Reef Marine Park Authority 2009). Activities such as fishing, diving, boating, tourism, and research are permitted in the park but are regulated through a system of zoning that governs where activities can and cannot occur.

Commercial fishing is the largest extractive activity in the GBRMP and includes the major commercial fisheries of prawn trawling, reef line fishing, and inshore netting and crabbing, as well as smaller dive-based fisheries for tropical rock lobster, aquarium fishes, coral, sea cucumber, trochus, and specimen shells. Commercial fisheries in the GBRMP contribute approximately $\$ 139$ million to local economies annually (GBRMPA 2009). Additionally, a robust charter-fishing sector operates in the GBRMP, providing opportunities for people to access recreational fishing in the park and contributing an additional (but unquantified) amount to local economies.

In July 2004, the GBRMPA implemented a new zoning plan for the GBRMP that increased "no-take" (i.e., no fishing) areas from $5 \%$ to $33 \%$ of the total park area, and increased additional "no-trawling" areas from $15 \%$ to $28 \%$ of the total park area. The primary aim of the rezoning was to increase the level of protection afforded to the biodiversity of the GBR (Fernandes et al. 2005). As part of the rezoning process, the GBRMPA made significant efforts to engage with the commercial, charter, and recreational fishing sectors, other industries (e.g., tourism) and members of the general community in an effort to minimize the impacts of the rezoning on stakeholders (Fernandes et al. 2005). The Australian government also committed to a structural adjustment package to assist fishers, fishery-related businesses, employees, and communities adversely affected by the rezoning, and to manage displaced fishing effort that could have unsustainable ecological or economic impacts (Macintosh et al. 2010). Adjustments were available to allow fishers to exit the fishing industry, restructure their business, and assist employees, communities, and regions that experienced social and economic impacts. In total, the structural adjustment package distributed approximately $\$ 250$ million to fishers and associated industries affected by the rezoning (Macintosh et al. 2010).

Lédée et al. (2012) examined the responses and adaptation strategies of commercial and charter fishers to the 2004 GBR zoning plan 5 yrs after its implementation. They found that fishers were generally unsupportive of the zoning plan because of their perceptions that they were not adequately consulted during the planning process and their perceptions of a range of impacts on their fishing business. Lédée et al. (2012) also found that many fishers had begun to adapt to the new zoning plan and that the extent of adaptation was related to fishers' perceptions about the impacts of the zoning plan on their fishing activity.

In this paper, we reexamine commercial fishers' responses and adaptations to the 2004 GBR rezoning from a social resilience perspective. Our objective is to use the 2004 GBR rezoning to gain insight into how social resilience influences perceptions about and adaptation to real-world policy change experienced by fishers. Based on previous theory and research into social resilience, we expect that fishers who have higher levels of social resilience will have more positive perceptions about the 2004 zoning plan and its long-term goals and outcomes, will perceive lower impacts from the plan, and will 
Table 1. Descriptive statistics and reliability analysis for the social resilience scale for Queensland commercial fishers

\begin{tabular}{|c|c|c|c|c|}
\hline$\underline{\text { Social resilience scale items }(\alpha=0.70)}$ & Mean $^{\dagger}$ & SD & $\begin{array}{l}\text { Item-total } \\
\text { correlation }\end{array}$ & $\begin{array}{l}\alpha \text { if item } \\
\text { deleted }\end{array}$ \\
\hline I am confident I could get work elsewhere if I needed to & 3.14 & 1.35 & 0.43 & 0.66 \\
\hline I would be nervous trying something else ${ }^{\ddagger}$ & 3.05 & 1.36 & 0.38 & 0.67 \\
\hline I am more likely to adapt to change compared with other fishers I know & 3.37 & 1.11 & 0.45 & 0.66 \\
\hline I am confident things will turn out well regardless of change & 2.95 & 1.17 & 0.26 & 0.68 \\
\hline I have many career options available to me if I decide to no longer be a fisher & 2.33 & 1.17 & 0.47 & 0.65 \\
\hline Every time there is a new change I plan a way to make it work for me & 3.59 & 0.89 & 0.23 & 0.69 \\
\hline If there are any more changes I will not survive much longer ${ }^{*}$ & 3.70 & 1.16 & 0.30 & 0.68 \\
\hline I can cope with small changes in the industry & 3.47 & 0.94 & 0.31 & 0.68 \\
\hline I am too young to retire and too old to find work elsewhere & 3.41 & 1.28 & 0.46 & 0.65 \\
\hline I have planned for my financial security & 3.36 & 1.01 & 0.18 & 0.69 \\
\hline I am not competitive enough to survive much longer & 2.62 & 1.16 & 0.21 & 0.69 \\
\hline I am interested in learning new skills outside of the industry & 2.52 & 1.20 & 0.22 & 0.69 \\
\hline
\end{tabular}

show higher levels of adaptation to the plan than fishers with lower levels of social resilience.

\section{METHODS}

Face-to-face interviews with commercial line, trawl, and charter fishers were conducted during visits to ports along the GBR coast (Gladstone, Yeppoon, Mackay, Townsville, Cairns, and Port Douglas) during 2008 and 2009. Active fishers were chosen from a contact database maintained by the Fishing and Fisheries Research Centre at James Cook University and through contacts supplied by the commercial fishing representative body (the Queensland Seafood Industry Association) and the state fisheries management agency (Fisheries Queensland). Prior to port visits, a random sample of fishers was contacted by telephone and invited to participate in the survey. Fishers who agreed to participate were contacted again during the port visit and a time and place to conduct the survey was arranged. During port visits, the list of active fishers was updated with information obtained from fishers in the area. When fishers who had agreed to participate in the survey could not be re-contacted during the port visit, alternative fishers were selected from the updated fisher list and asked to participate in the survey. In total, 114 interviews with active fishers were conducted (line $=53$; trawl $=21$; charter $=40$ ).

The survey instrument was developed in consultation with active fishers and the GBRMPA. To measure fishers' social resilience, fishers were asked to rate their level of agreement (on a five-point scale ranging from $1=$ strongly disagree to $5=$ strongly agree) with 12 statements about their perceived ability to cope with changes in the fishing industry (Table 1; Marshall and Marshall 2007). A social resilience (SR) score for each fisher was derived by calculating the mean response score across all 12 statements. Cronbach's alpha of 0.70 indicated an acceptable level of reliability for the 12-item SR scale (Table 1).
Fishers were asked about their attitudes and perceptions regarding the 2004 GBR zoning plan, the effects of the plan on their fishing activity and fishing business, and their beliefs about the zoning plan and management of the GBR. Closedended, five-point response scales were used to measure fishers' attitudes and perceptions. For analysis purposes, the five-point scales were collapsed into three-point ordinal scales by combining the two most extreme categories on each end of the scale into a single category on each end of the scale (Jacoby and Matell 1971).

The effects of fishers' personal and business characteristics on fishers' SR score were examined using general linear models. Personal variables tested included: age, percentage of household income from fishing, household size, number of dependent children, years of experience as a commercial fisher, house ownership (classified as renting, own outright, or own with a mortgage), number of immediate family members involved in the fishing industry, and years of formal education attained. Business characteristics tested included: fishing sector (i.e., charter, line, trawl), business type (classified as either owner-operator, license owner (nonoperator), contract skipper, or license lessee), number of vessels operated, and target diversity. For line and trawl fishers, target diversity was measured by recording the number of endorsements (i.e., permits) attached to the fisher's license (each endorsement allows the fisher to access a particular fishery, each of which may include more than one species). For charter fishers (who are not required to possess endorsements), target diversity was measured by recording the number of species that the fisher primarily targets. To identify potential indicators of social resilience, the relationship between SR score and each of the 12 personal and business characteristic variables was examined separately using general linear models (i.e., ANOVA with Tukey's post hoc test for categorical variables, linear regression for continuous variables). To identify the best predictors of social 
resilience, a combined general linear model was estimated that included all 12 independent variables. Non-significant (i.e., $p$ $>0.05$ ) variables were then removed and the model was re-fit to determine the most parsimonious model.

The effects of SR score on fishers' opinions about management of the GBR, attitudes toward the 2004 zoning plan, and perceptions of the impacts of the rezoning were tested using proportional odds logistic regression. This method is appropriate for an ordinal response variable when the effects of the explanatory variable on movement between categories of the response variable are the same across all levels of the response variable (i.e., proportional odds is assumed) (Agresti 1996). The three-point ordinal measures of opinions, attitudes, and perceptions were used as the response variables in the analysis, and the score test was used to confirm that the proportional odds assumption was met for all models $(p>0.05$ for all). The effect of SR score on whether fishers applied for compensation under the structural adjustment program was tested using binary logistic regression. Odds ratios for a oneunit increase in SR score are presented as measures of effect size for all significant relationships (odds ratio for an $\mathrm{X}$ unit increase in SR score $=\mathrm{e}^{\mathrm{X}(\ln [\text { odds ratio }))}$ ).

\section{RESULTS}

Most fishers (96\%) were male, ranging in age from 23 yrs to 77 yrs (mean age $=50.5 \mathrm{yrs}$ ). Fishing experience ranged from 2 yrs to 48 yrs with a mean of 22 yrs. Fishing was the sole source of household income for $70 \%$ of fishers; on average, fishers reported that $83 \%$ of their household income comes from fishing. Most fishers owned their own home, either with a mortgage $(47 \%)$ or outright $(36 \%)$. Sixty-four percent of fishers reported having received the equivalent of Yr 10 level of education or less; $28 \%$ reported having received a highschool level of education or greater. Most fishers lived in a household with either one $(47 \%)$, two $(13 \%)$, or three $(20 \%)$ other people (mean household size (including the fisher) $=2.6$ people). Most fishers (65\%) had no dependent children under the age of $18 ; 10 \%$ of fishers had one dependent child and $25 \%$ had two or more dependent children. On average, fishers had 1.4 immediate family members involved in the fishing industry $(\min =0 ; \max =10)$. Seventy-nine percent of surveyed fishers were owner-operators of the fishing business about which they were questioned; the remainder were either contract skippers $(12 \%)$, the license owner $(5 \%)$, or leasing the license (4\%). Eighty-four percent of fishers operated only one fishing vessel, and a majority of fishers reported relying primarily on either one $(26 \%)$, two $(22 \%)$, or three $(41 \%)$ species/endorsements.

Average SR score for the sample of 114 fishers was 2.99 (SD $=0.56 ; \min =1.83 ; \max =4.5$ ) out of a possible maximum of 5 . When tested separately, there were significant effects of four personal variables and two business characteristic variables on SR score. Age, yrs of fishing experience, percentage of household income derived from fishing, and number of immediate family members involved in the fishing industry had a significant negative effect on social resilience score (Fig. 1). There was a significant effect of fishery sector on social resilience score $(F=6.38 ; p=0.002)$. Trawl fishers $(\mathrm{SR}=2.64)$ had significantly lower social resilience than both charter fishers $(\mathrm{SR}=3.15)$ and line fishers $(\mathrm{SR}=3.02)$ (Fig. $1)$. The number of species/endorsements that fisheries relied upon had a negative effect on social resilience $(F=2.74 ; p=$ $0.04)$. Fishers who relied on four or more species/ endorsements had higher social resilience $(\mathrm{SR}=3.36)$ than fishers who relied on only one species/endorsement $(\mathrm{SR}=$ 2.81); Fig. 1). There was no significant effect of education level, household size, number of dependent children, home ownership, business type, or number of primary vessels operated on SR score. When all 12 independent variables were combined into a single general linear model, only age, experience, and percentage of income received from fishing were significant predictors of SR score (Table 2).

Fig. 1. Significant relationships between social resilience score and personal and fishing characteristic variables for the sample of Queensland commercial fishers. Category means with the same letter are significantly different $(p<$ $0.05)$.
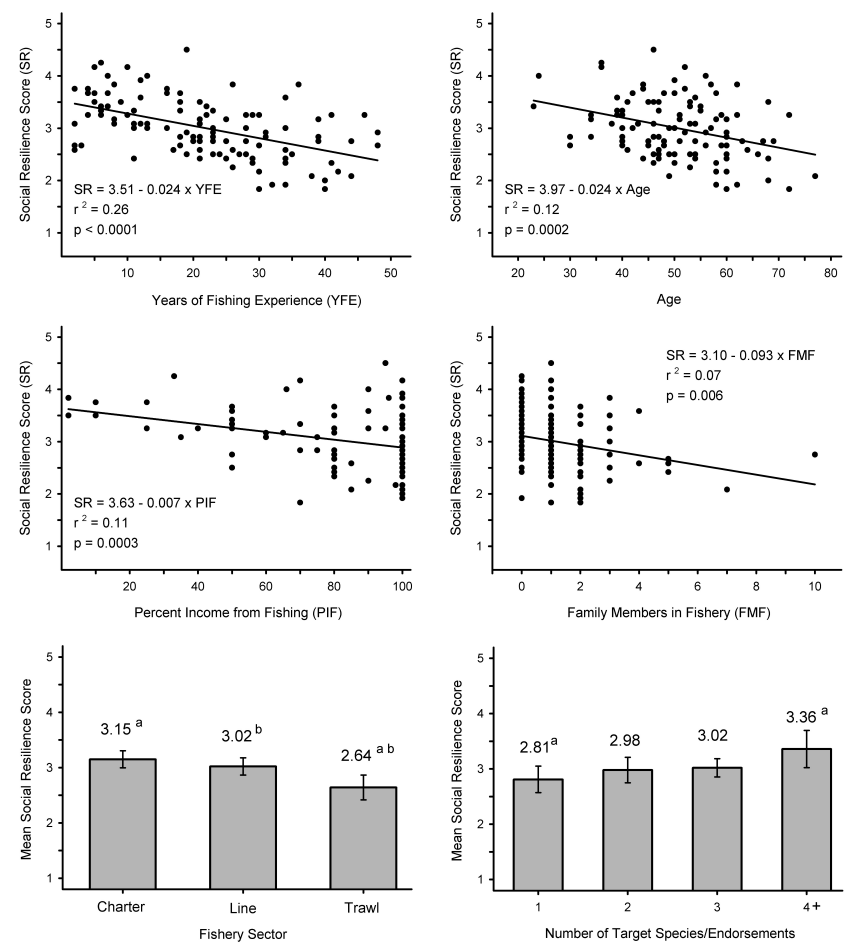
Table 2. Results of the general linear model testing the combined effects of the eight personal and business characteristics on Queensland commercial fishers' social resilience score. Only significant variables have been included in the final model. $\dagger$

\begin{tabular}{|c|c|c|c|c|c|}
\hline Parameter & df & $\mathrm{B}$ & SE & $F$ & $p$ \\
\hline Intercept & 1 & 4.28 & 0.29 & 213.7 & $<0.0001$ \\
\hline Age & 1 & -0.01 & 0.005 & 4.25 & 0.04 \\
\hline Experience & 1 & -0.016 & 0.004 & 13.18 & 0.0004 \\
\hline $\begin{array}{l}\text { Percentage of } \\
\text { income from } \\
\text { fishing }\end{array}$ & 1 & -0.005 & 0.004 & 6.12 & 0.02 \\
\hline \multicolumn{6}{|c|}{$\begin{array}{l}\text { Model statistics: } n=109 ; F=16.15 ; p<0.0001 ; r^{2}=0.32 \\
\text { Non-significant variables excluded from the final model were: } \\
\text { education level }(\mathrm{df}=6 ; F=0.65 ; p=0.69) \text {, household size }(\mathrm{df}= \\
1 ; F=0.41 ; p=0.52) \text {, sector }(\mathrm{df}=2 ; F=1.28 ; p=0.28) \text {, target } \\
\text { diversity, }(\mathrm{df}=1 ; F=2.53 ; p=0.11) \text {, business type }(\mathrm{df}=1 ; F= \\
0.18 ; p=0.67) \text {, number of primary vessels operated }(\mathrm{df}=1 ; F= \\
0.21 ; p=0.65) ; \text { number of family members in the fishing industry } \\
(\mathrm{df}=1 ; F=3.2 ; p=0.08) \text {, number of dependent children }(\mathrm{df}=1 \text {; } \\
F=0.01 ; p=0.94) \text {, and home ownership ( } \mathrm{df}=2 ; F=0.76 ; p= \\
0.46) \text {. }\end{array}$} \\
\hline
\end{tabular}

A majority of fishers believed that rezoning the GBRMP was a bad idea (bad idea $=55 \%$; neutral $=10 \%$; good idea $=35 \%$ ) and that the amount of area covered by no-take zones in the area where they fish was too much (too much $=62 \%$; just enough $=23 \%$; too little $=15 \%$ ). Likewise, most fishers reported being opposed to the zoning plan at the time of the survey (oppose $=73 \%$; neutral $=6 \%$; support $=21 \%$ ). There was a significant positive effect of SR score on whether fishers believed the rezoning was a good idea $\left(\chi^{2}=9.5 ; p=0.002\right.$; odds ratio $=2.96$ ), fishers' belief that "too little" area was covered by no take zones $\left(\chi^{2}=8.9 ; p=0.003\right.$; odds ratio $=$ $3.00)$, and fishers' support for the zoning plan $\left(\chi^{2}=5.8 ; p=\right.$ 0.01 ; odds ratio $=2.56$ ). Fishers' responses to seven additional statements about management of the GBR, and effect of SR score on responses to those statements, are presented in Table 3. SR score had a significant effect on responses to four of the seven statements. Fishers with higher SR scores were more likely to believe that the rezoning plan was necessary, that fishers were treated fairly in the rezoning process, that commercial fishers were adequately consulted about the zoning plan, and that the GBRMPA can be trusted to do what is best for conservation of the GBR. There was no effect of SR score on whether fishers believed that biodiversity protection is the most important goal of GBR management, whether the GBRMPA could be trusted to consider the concerns of commercial fishers, or whether fishers were adequately compensated for areas lost under the 2004 zoning plan.

When asked about the overall effects of the zoning plan on their fishing business, most fishers said it was negative (negative impact $=82 \%$; no impact $=13 \%$; positive impact $=$ $5 \%$ ). There was a significant positive effect of SR score on fishers' perceptions of the overall impact of the zoning plan (i.e., fishers with higher SR scores were more likely to perceive neutral or positive impacts from the rezoning than were fishers with lower SR scores; $\chi^{2}=5.3 ; p=0.02$; odds ratio $=2.91$ ). Fishers' perceptions of the specific impacts of the zoning plan on 11 aspects of their fishing activity and fishing business, and the relationship between those perceptions and SR score, are presented in Table 4 . There was a significant relationship between SR score and six of the 11 perceived impacts. Fishers with higher SR scores were less likely to perceive negative impacts in terms of their access to productive fishing areas, the number of fish they catch, the income they receive from fishing, the profitability of their business, their satisfaction with commercial fishing, and their sense of security as a commercial fisher. There was no relationship between SR score and perceived impacts of the zoning plan on the longterm sustainability of the GBR or GBR fisheries, the impact of commercial or recreational fishing on the GBR, or the size of the fish that fishers catch.

Most fishers (62\%) reported applying for compensation under the structural adjustment plan. SR score had a significant negative effect on the likelihood of fishers applying for structural adjustment (odds ratio $=0.27 ; p=0.0009$ ). Most fishers reported that they adapted their fishing activity and fishing business either moderately well $(48 \%)$ or very well (27\%) to the zoning plan in the 5 yrs after its implementation (not well $=25 \%$ ). SR score had a significant positive influence on the degree to which fishers adapted their fishing activity and fishing business to the new zoning plan $\left(\chi^{2}=15.6 ; p<\right.$ 0.0001 ; odds ratio $=4.04)$. Most fishers reported that they were either moderately likely (34\%) or very likely $(47 \%)$ to still be involved in the commercial fishing industry within 3 yrs (not likely $=19 \%$ ). SR score had a significant positive relationship on fishers' perceived likelihood of still being involved in the industry in $3 \mathrm{yrs}\left(\chi^{2}=6.77 ; p=0.01\right.$; odds ratio $\left.=2.47\right)$.

\section{DISCUSSION AND CONCLUSIONS}

We found a strong relationship between commercial fishers' SR level and their beliefs about and reaction to the 2004 GBR zoning plan. Fishers with higher resilience were more likely to believe that the zoning plan was necessary, more likely to be supportive of the plan, and more likely to have adapted their fishing business and fishing activity to the plan than were fishers with lower social resilience. High-resilience fishers were also less likely to perceive negative impacts of the plan on their fishing business, less likely to have negative attitudes toward the public consultation process, and less likely to have applied for financial compensation under the structural adjustment program. Resilience theory predicts that resource users with high levels of social resilience will have greater capacity to cope with and adapt to adverse events that alter their access to the resources they depend on (Marshall and Marshall 2007, Levin et al. 1998). Previous studies have found 
Table 3. Queensland commercial fishers' level of agreement with statements about management of the Great Barrier Reef, and results of proportional odds logistic regression models testing the relationship between each statement and social resilience (SR) score.

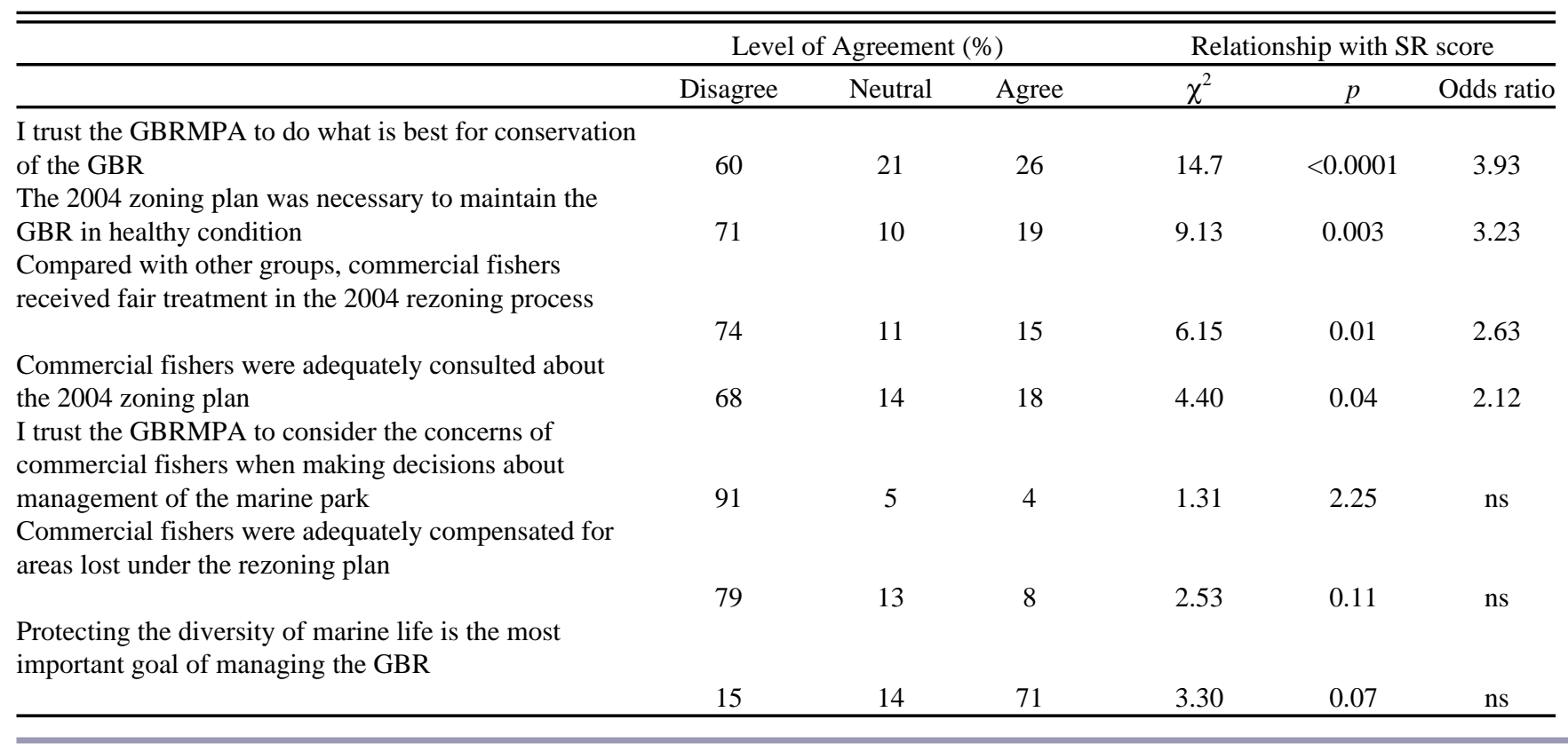

a positive relationship between social resilience and the ways in which commercial fishers assess, appreciate, experience, and respond to hypothetical policy change (Marshall 2007, Marshall et al. 2009). Ours is the first study to demonstrate a relationship between social resilience and the way in which commercial fishers perceive and respond to change events that they have experienced. These results confirm the utility of the social resilience concept and measurement scale (Marshall and Marshall 2007) for the a priori identification of fishers likely to be vulnerable to changes and for the identification of fishers who are struggling to cope with change events.

Based on these results, we hypothesize that fostering and maintaining a high level of social resilience among GBR commercial fishers would be an effective way of reducing the social, economic, transactional, and financial costs of future policy changes that affect fishers' access to resources. Our results suggest that social and economic costs of policy changes borne by individual fishers would be reduced by maintaining high social resilience because highly resilient fishers will be less likely to perceive specific impacts of policy change on their fishing activity and will adapt to changes in access to fisheries resources more rapidly. Transactional costs of implementing new policy change would be reduced because highly resilient fishers will likely be more trusting of the management authority and more accepting of new policies aimed at conserving the GBR and its fisheries. Finally, the financial costs associated with compensating affected fishers would be reduced because highly resilient fishers will be less likely to request compensation under structural adjustment programs. Although the need to manage for the ecological resilience of the GBR ecosystem is central to management of the marine park (Great Barrier Reef Marine Park Authority 2009), the value of managing for the social resilience of resource users is not well established in GBR management. The need for minimizing the costs of managing the GBR is well recognized, however, and significant effort has been expended to minimize management costs, including social and economic impacts on resource users (McCook et al. 2010, Fernandes et al. 2005). We suggest that the concept of resilience in the context of GBR management needs to be broadened to include social dimensions, and that doing so would not be inconsistent with current management goals in the GBR. Actively managing for social resilience and incorporating into decision making knowledge about the factors that confer or erode social resilience would aid in the design and implementation of policies that minimize impacts on people while enhancing the sustainability of the GBR ecosystem (Adger 2000, Brunckhorst 2002).

Managing for resilience requires an understanding of the key components of social resilience, how these key components are affected by external drivers, and how social resilience can be fostered and sustained (Walker et al. 2002, Cinner et al. 2009). The operationalization of social resilience used in this study was designed to measure fishers' perceptions of risk, coping, planning/learning, and ability to adapt to change. In other words, the key components of social resilience studied 
Table 4. Queensland commercial fishers' perceptions of the impacts of the 2004 Great Barrier Reef zoning plan on various aspects of their fishing business and fishing activity, and results of proportional odds logistic regression models testing the relationship between perceived impact and social resilience (SR) score.

\begin{tabular}{|c|c|c|c|c|c|c|}
\hline & \multicolumn{3}{|c|}{ Perceived Effect $(\%)$} & \multicolumn{3}{|c|}{ Relationship with SR score } \\
\hline & Decreased & No effect & Increased & $\chi^{2}$ & $p$ & Odds ratio \\
\hline Access to productive fishing areas & 85 & 12 & 3 & 7.07 & 0.008 & 3.18 \\
\hline Number of fish caught & 61 & 34 & 5 & 5.72 & 0.02 & 2.37 \\
\hline Personal income from fishing & 76 & 22 & 2 & 9.11 & 0.002 & 3.79 \\
\hline Fishing business profitability & 82 & 17 & 1 & 10.4 & 0.001 & 5.07 \\
\hline Satisfaction with job as a commercial fisher & 68 & 27 & 5 & 8.42 & 0.004 & 3.03 \\
\hline Sense of security as a commercial fisher & 81 & 16 & 3 & 5.37 & 0.02 & 2.84 \\
\hline Long-term sustainability of GBR fisheries & 41 & 33 & 26 & 3.54 & 0.06 & ns \\
\hline Long-term sustainability of the GBR & 10 & 48 & 42 & 2.37 & 0.12 & ns \\
\hline Impact of commercial fishing on the GBR & 34 & 41 & 25 & 1.29 & 0.26 & ns \\
\hline Impact of recreational fishing on the GBR & 19 & 52 & 29 & 1.18 & 0.27 & ns \\
\hline Size of fish caught & 30 & 64 & 6 & 1.80 & 0.17 & $\mathrm{~ns}$ \\
\hline
\end{tabular}

here are the individual's subjective beliefs about his or her abilities to learn, plan, manage risk, cope, and adapt, rather than objective measures of fishers' abilities on these dimensions. Our results, along with the results of Marshall et al. (2007), provide clear evidence that the subjective beliefs underlying social resilience are related to a range of demographic and business characteristics. Marshall (2007) also provides evidence that these subjective beliefs can be influenced by elements of the policy development process (that is, level of engagement in the decision-making process, rate of implementation of policy change). Collectively, these results demonstrate that social resilience is a complex concept consisting of multiple psychological, behavioral, experiential, social structural, and business/financial dimensions. As a consequence of this complexity, understanding how (or even if) social resilience can be fostered, sustained, or enhanced through intervention will not be an easy task. More research is needed, particularly into the psychological and socialpsychological processes that underlie the formation, maintenance, and erosion of individuals' subjective beliefs about their abilities to learn, plan, manage risk, cope, and adapt and into the relationship among these beliefs, individuals' capacity to act, and their patterns of coping and adaptation behavior. An important question relevant to enhancing social resilience through intervention concerns the relationship between subjective beliefs and demographic and business characteristic variables, i.e., can subjective beliefs about ability to learn, plan, manage risk, cope, and adapt be altered independently of fishers' age, experience level, occupational attachment, business structure, etc., and if so, how can this alteration be accomplished?

Conceptualizing social resilience as consisting of multiple psychological, behavioral, experiential, social structural, and business/financial dimensions also raises the question of how such a concept should be measured. As discussed previously, the operationalization of social resilience used in this study taps into the psychological dimensions only. The reliance on perceptions alone as a measure of fishers' ability to cope with and adapt to change may be problematic because other dimensions may have different effects on coping and adapting abilities, and because perceptions may be more easily influenced by external variables (e.g., the policy development process; the process and experience of adapting to change, etc.; Marshall 2007). Future studies should explore the potential for incorporating a wider range of indicators in the measurement of social resilience, including more objective measures of fishers' ability to plan, learn, reorganize, and cope with change (e.g., education, migration history, participation in decision making/consultation programs, etc., [cf. Cinner et al. 2009]) . Our results suggest a number of demographic and business characteristic variables that could be incorporated into measures of social resilience (e.g., age, fishing experience, fishery sector, target diversity, occupational attachment, business size, resource dependence). However, further research is needed to identify and test indicators and indices that tap into and measure additional dimensions of the social resilience concept.

A number of methodological limitations must be acknowledged when interpreting or applying the results of this study. First, we were not able to include fishers who exited the fishing industry as a result of the rezoning. Clearly, information about the resilience level of these fishers before their decision to exit the industry, their reasons for exiting the industry, and their adaptation and coping strategies after exiting would provide valuable insights into the social resilience concept and its relationship to adaptive behaviors. Future studies should endeavor to identify and include resource users who have undergone such transformational shifts in response to policy change and determine the relationship among social resilience, exiting decisions, and 
subsequent coping and adaptation behaviors. Second, although we were able to show that fishers with higher resilience levels were coping better and adapting more quickly to the rezoning, we did not collect any information on the actual coping or adaptation strategies employed by fishers. Therefore, our understanding of how and why higher social resilience levels translate into lower impacts and quicker adaptation remains limited and requires further investigation. Finally, our conclusion that high-resilience fishers had more positive perceptions of the 2004 GBR zoning plan and were better able to cope with and adapt to its impacts rests partly on the assumption that the resilience levels of individual fishers were similar (at least relative to other fishers) before and after the rezoning. It is possible, however, that fishers' experiences with the changes imposed by the zoning plan influenced their beliefs about their ability to learn, plan, manage risk, cope, and adapt (Marshall 2007). Because we measured the social resilience of fishers only after they had experienced and begun to adapt to the changes imposed by the zoning plan, we were not able to determine the extent to which fishers' resilience level following rezoning was influenced by the ways in which they were impacted by and responded to the changes imposed by the zoning plan. Further research that follows resource users through adaptation processes is necessary to understand more fully the ways in which the process of dealing with change events can enhance or erode the social resilience of individuals.

The importance of incorporating information about resource users and the impacts of policy change on their values and activities into natural resource decision making is well established (Clay and McGoodwin 1995, Lane and Stephenson 1995, Charles and Wilson 2009). Likewise, resilience theory has shown potential for enhancing our ability to combine information from the social and natural sciences in support of balancing social costs with sustainability goals in resource management (Berkes and Folke 1998). However, operationalizing and applying the resilience framework and its various components within a natural resource management context remains challenging. In this paper, we used a specific operationalization of social resilience (Marshall and Marshall 2007) to demonstrate a strong relationship between the resilience level of commercial fishers and their perceptions of and responses to a major change in their access to fisheries resources in the Great Barrier Reef Marine Park. We conclude that managing for social resilience in the GBR would aid in the design and implementation of policies that minimize the impacts on resource users and lead to more inclusive and sustainable management. Looking past the GBR system, our results provide evidence in support of the argument that strengthening capacity to manage resilience (including social resilience) is critical for achieving positive ecological and social outcomes from coupled social-ecological systems (Lebel et al. 2006). The social resilience concept and associated measurement scale provide a valuable tool for predicting and understanding the responses of resource users to environmental or policy change and for enabling this information to be incorporated into decision making. However, our results suggest that further research is necessary to better understand the multidimensional nature of social resilience, how it can be operationalized and quantified, how it can be fostered and sustained, and how it can be effectively incorporated into resource management. Likewise, further testing and application of the social resilience framework outside of the Great Barrier Reef commercial fisher context is recommended to determine its utility in other fisher populations and other natural resource dependent industries.

Responses to this article can be read online at: http://www.ecologyandsociety.org/vol17/iss3/art6/responses/

\section{Acknowledgments:}

We thank Wendi Parsons, Ann Penny, John Daicopoulos, Andrew Chin, and Tom Brewer for conducting interviews with fishers. Special thanks to all of the line, charter, and trawl fishers who participated in the survey; this project could not have been conducted without their cooperation and support. This study was funded by the Australian Government's Marine and Tropical Sciences Research Facility (MTSRF).

\section{LITERATURE CITED}

Adger, W. N. 2000. Social and ecological resilience: Are they related? Progress in Human Geography 24:347-364. http://d x.doi.org/10.1191/030913200701540465

Adger, W. N., P. M. Kelly, A. Winkels, L. Q. Huy, and C. Locke. 2002. Migration, remittances, livelihood trajectories, and social resilience. Ambio 31(4):358-366.

Agresti, A. 1996. An introduction to categorical data analysis. John Wiley and Sons, New York, New York, USA. http://dx. doi.org/10.1002/0470114754

Berkes, F., and C. Folke. 1998. Linking social and ecological systems for resilience and sustainability. Pages 1-25 in F. Berkes and C. Folke, editors. Linking social and ecological systems: management practices and social mechanisms for building resilience. Cambridge University Press, Cambridge, UK.

Brunckhorst, D. J. 2002. Institutions to sustain ecological and social systems. Ecological Management and Restoration 3:108-16. http://dx.doi.org/10.1046/j.1442-8903.2002.00102. $\underline{\mathrm{X}}$

Carpenter, S., B. Walker, M. Anderies, and N. Abel. 2001. From metaphor to measurement: resilience of what to what? Ecosystems 4:765-781. http://dx.doi.org/10.1007/s10021-001 -0045-9

Charles, A., and L. Wilson. 2009. Human dimensions of marine protected areas. ICES Journal of Marine Science: 
Journal du Conseil 66:6-15. http://dx.doi.org/10.1093/icesjms/ $\underline{\mathrm{fsn} 182}$

Cinner, J., M. M. P. B. Fuentes, and H. Randriamahazo. 2009. Exploring social resilience in Madagascar's marine protected areas. Ecology and Society 14(1):41. [online] URL: http://ww w.ecologyandsociety.org/vol14/iss1/art41/

Clay, P. M., and J. R. McGoodwin. 1995. Utilizing social sciences in fisheries management. Aquatic Living Resources 8:203-207. http://dx.doi.org/10.1051/alr:1995019

Fernandes, L., J. Day, A. Lewis, S. Slegers, B. Kerrigan, D. Breen, D. Cameron, B. Jago, J. Hall, D. Lowe, J. Innes, J. Tanzer, V. Chadwick, L. Thompson, K. Gorman, M. Simmons, B. Barnett, K. Sampson, G. De'Ath, B. Mapstone, H. Marsh, H. Possingham, I. Ball, T. Ward, K. Dobbs, J. Aumend, D. Slater, and K. Stapleton. 2005. Establishing representative no-take areas in the Great Barrier Reef: largescale implementation of theory on marine protected areas. Conservation Biology 19:1733-1744. http://dx.doi.org/10.1111/ j.1523-1739.2005.00302.x

Great Barrier Reef Marine Park Authority. 2009. Great Barrier Reef Outlook Report 2009. Great Barrier Reef Marine Park Authority, Townsville, Australia.

Gunderson, L. 1999. Resilience, flexibility, and adaptive management-antidotes for spurious certitude? Conservation Ecology 3(1):7. [online] URL: http://www.consecol.org/vol3/ iss1/art7

Holling, C. S. 2004. From complex regions to complex worlds. Ecology and Society 9(1):11. [online] URL: http://www.ecolo gyandsociety.org/vol9/iss1/art11

Holling, C. S., F. Berkes, and C. Folke. 1998. Science, sustainability, and resource management. Pages 342-362 in F. Berkes and C. Folke, editors. Linking social and ecological systems; management practices and social mechanisms for building resilience. Cambridge University Press, Cambridge, UK.

Holling, C. S., and G. K. Meffe. 1996. Command and control and the pathology of natural resource management. Conservation Biology 10:328-337. http://dx.doi.org/10.1046/ j.1523-1739.1996.10020328.x

Hughes, T. P., D. R. Bellwood, C. Folke, R. S. Steneck, and J. E. Wilson. 2005. New paradigms for supporting the resilience of marine ecosystems. Trends in Ecology and Evolution 20(7):380-386. http://dx.doi.org/10.1016/j.tree.200 $\underline{5.03 .022}$

Jacoby, J., and M. S. Matell. 1971. Three-point Likert scales are good enough. Journal of Marketing Research 8(4):495500.
Lane, D. E., and R. L. Stephenson. 1995. Fisheries management science: the framework to link biological, economic and social objectives in fisheries management. Aquatic Living Resources 8:215-221. http://dx.doi.org/10.1051/ alr:1995021

Lebel, L., J. M. Anderies, B. Campbell, C. Folke, S. HatfieldDodds, T. P. Hughes, and J. Wilson. 2006. Governance and the capacity to manage resilience in regional social-ecological systems. Ecology and Society 11(1):19. [online] URL: http:// www.ecologyandsociety.org/vol11/iss1/art19/.

Lédée, E. J. I, S. G. Sutton, R. C. Tobin, and D. M. De Freitas. 2012. Responses and adaptation strategies of commercial and charter fishers to zoning changes in the Great Barrier Reef Marine Park. Marine Policy 36:226-234. http://dx.doi.org/10 .1016/j.marpol.2011.05.009

Levin, S., S. Barrett, S. Aniyar, W. Baumol, C. Bliss, B. Bolin, P. Dasgupta, P. R. Ehrich, C. Folke, I. Gren, C. S. Holling, A. Jansson, B. Jansson, K. Maler, D. Martin, C. Perrings, and E. Sheshinski. 1998. Resilience in natural and socioeconomic systems. Environment and Development Economics 3:222235. http://dx.doi.org/10.1017/S1355770X98240125

Macintosh, A., T. Bonyhady, and D. Wilkinson. 2010. Dealing with interests displaced by marine protected areas: a case study on the Great Barrier Reef Marine Park Structural Adjustment Package. Ocean and Coastal Management 53:581-588. http: //dx.doi.org/10.1016/j.ocecoaman.2010.06.012

Marshall, N. A. 2007. Can policy perception influence social resilience to policy change? Fisheries Research 86:216-227. http://dx.doi.org/10.1016/j.fishres.2007.06.008

Marshall, N. A., D. M. Fenton, P. A. Marshall, and S. G. Sutton. 2007. How resource-dependency can influence social resilience within a primary resource industry. Rural Sociology 72(3):359-390.

Marshall, N. A., and P. A. Marshall. 2007. Conceptualizing and operationalizing social resilience within commercial fisheries in northern Australia. Ecology and Society 12(1):1. [online] URL: http://www.ecologyandsociety.org/vol12/iss1/ $\underline{\operatorname{art} 1}$

Marshall, N., P. Marshall, and A. Abdulla. 2009. Using social resilience and resource dependency to increase the effectiveness of marine conservation initiatives in Salum, Egypt. Journal of Environmental Planning and Management 52:901-918. http://dx.doi.org/10.1080/09640560903180982

McCook, L. J., T. Ayling, M. J. Cappo, H. Choate, R. D. Evans, D. M. De Freitas, M. Heupel, T. P. Hughes, G. P. Jones, B. Mapstone, H. Marsh, M. Mills, F. J. Molloya, C. R. Pitcher, R. L. Pressey, G. R. Russ, S. G. Sutton, H. Sweatman, R. 
Tobin, D. R. Wachenfeld, and D. H. Williamson. 2010. Adaptive management of the Great Barrier Reef: a globally significant demonstration of the benefits of networks of marine reserves. Proceedings of the National Academy of Sciences 107(43):18278-18285. http://dx.doi.org/10.1073/pnas.0909335107

Walker, B., S. Carpenter, J. Anderies, N. Abel, G. S. Cumming, M. Janssen, L. Lebel, J. Norberg, G. D. Peterson, and R. Pritchard. 2002. Resilience management in socialecological systems: a working hypothesis for a participatory approach. Conservation Ecology 6(1):14. [online] URL: http: //www.consecol.org/vol6/iss1/art14 